\title{
Metamorfismo de contato nas rochas da Formação Irati (Permiano), norte da Bacia do Paraná
}

\author{
Camila Wense Dias dos Anjos ${ }^{1}$ \& Edi Mendes Guimarães ${ }^{2}$
}

\begin{abstract}
Resumo A Formação Irati (Permiano), constituída por uma seqüência de folhelhos negros e rochas carbonáticas, é intrudida por rochas básicas pós-Triássicas. Em Perolândia (GO), a pedreira SUCAL exibe uma soleira de no máximo treze metros encaixada na Formação Irati. Para investigar as alterações minerais provocadas pelo calor da soleira, amostras das rochas encaixantes, a diferentes distâncias da intrusão, foram analisadas por difração de raios X, microssonda eletrônica e microscopia eletrônica de varredura. Os resultados mostraram que os pelitos e rochas carbonáticas não afetados pelo calor da soleira são formados por saponita e dolomita respectivamente. Próximo à soleira formou-se talco, serpentina, piroxênio, calcita e plagioclásio. A partir do aparecimento dos três primeiros minerais, considerados minerais índices, foram identificadas as seguintes zonas de metamorfismo: Zona do Talco, Zona da Serpentina e Zona do Piroxênio, distribuídas de forma heterogênea acima e abaixo da intrusão. O confinamento de fluido aquoso na porção subjacente à intrusão favoreceu a formação de minerais hidratados (talco, serpentina), enquanto seu escape na porção superior possibilitou a formação de piroxênio e plagioclásio. O talco, a serpentina e a calcita formaram-se a partir da reação de dolomita com quartzo e fluido aquoso. O piroxênio e o plagioclásio são o produto da reação da saponita com quartzo e calcita. A temperatura máxima atingida nas zonas do talco e da serpentina não está clara, visto que os minerais índices são estáveis desde temperaturas ambientes a até $400-600^{\circ} \mathrm{C}$. Para a Zona do Piroxênio, a temperatura mínima para formação do piroxênio estaria em torno de $300-500^{\circ} \mathrm{C}$.
\end{abstract}

Palavras-chave: Formação Irati, metamorfismo de contato, saponita, talco, piroxênio.

\begin{abstract}
Contact metamorphism in the Permian Irati Formation, north part of Paraná Basin (Brazil). The Permian Irati Formation is a black shale-carbonate sequence that is intruded by Jurassic-Cretaceous basic rocks. In Goiás State, near Perolândia town, the SUCAL quarry exposes the Irati Formation with a diabase sill, less than thirteen meters thick. To investigate the mineral modifications caused by the heat of the sill, pelites and carbonate rocks were studied through X rays diffraction, electronic microprobe and scanning electronic microscopy. The results show that the pelites and carbonate rocks without sill influence are constituted by saponite and dolomite respectively. Near the sill talc, serpentine, pyroxene, calcite and plagioclase were formed. The first three minerals are considered index minerals and named the metamorphic zones: Talc Zone, Serpentine Zone and Pyroxene Zone that are heterogeneously distributed below and above the sill. The confinement of aqueous fluid below the intrusion favour the formation of hydrated minerals (talc, serpentine), but the fluid escape above the sill allowed the formation of pyroxene and plagioclase. Talc, serpentine and calcite were formed by the reaction of dolomite, quartz and aqueous fluid. Pyroxene and plagioclase are the products of the reaction of saponite with quartz and calcite. The temperature in the Talc and Serpentine zone is not clear, because the index minerals can be stable from room temperature up to $400-600^{\circ} \mathrm{C}$. In the Pyroxene Zone the minimum temperature for the formation of pyroxene could be estimated between 300 and $500^{\circ} \mathrm{C}$.
\end{abstract}

Keywords: Irati Formation, metamorphic contact, saponite, talc, pyroxene.

INTRODUÇÃO A Formação Irati (Permiano, Bacia do Paraná) é composta pela intercalação de rochas carbonáticas e folhelhos negros que podem conter até 30\% de matéria orgânica (White 1908a, Padula 1968). Com espessura máxima de 80 metros (Northfleet et al. 1969), esta unidade foi depositada em condições de mar restrito, progressivamente mais salino da base para o topo (Milani et al. 1994, Araujo et al. 2001). Em decorrência do seu potencial econômico e do seu conteúdo fossilífero - réptil Mesosaurus brasiliensis (Mac Gregor 1908) e flora de Glossopteris (White 1908) - a Formação Irati tornou-se objeto de numerosos estudos.

Assim como outras unidades da Bacia do Paraná, essa formação aloja corpos ígneos pós - triássicos, de rochas básicas e subsidiariamente alcalinas (Gomes 1959). Estima-se que aproximadamente $70 \%$ da área da Formação Irati esteja intrudida por soleiras, que variam de poucos metros a até cerca de 200 metros (Petri \& Fúlfaro 1983). A relevância de intrusões ígneas em seqüências sedimentares portadoras de matéria orgânica está tanto 
no incremento da temperatura, que influencia no grau de maturação da matéria orgânica (Araújo et al. 2000), como na migração de flúidos (Sant'Anna et al. 2006) e na formação de trapas para hidrocarbonetos (Eiras \& Wanderley Filho 2003, Wanderley Filho et al. 2006).

Os argilominerais, componentes principais dos folhelhos, são sensíveis a pequenas variações de temperatura, e são freqüentemente utilizados como indicadores de temperatura em auréolas de contato (Jaeger 1957, Girardi et al. 1978, Nadeau \& Reynolds 1981, Vergo \& April 1982, Aronson \& Lee 1986, Bühmann 1992).

No Estado de São Paulo, o halo térmico causado por intrusões ígneas nas rochas da Formação Irati é marcado pela formação de minerais metamórficos, como piroxênio e clorita, a partir da reação entre argilominerais e componentes carbonáticos das rochas sedimentares (Amaral 1971, Girardi et al. 1978).

Na borda norte da Bacia do Paraná também ocorrem intrusões ígneas alojadas na Formação Irati, como expostas nas frentes de lavra da Pedreira da SUCAL (GO) (Fig. 1). As alterações mineralógicas causadas pela intrusão compreendem a formação de piroxênio, serpentina e talco nas rochas encaixantes (Anjos 2003, Anjos \& Guimarães 2003). Análises de elementos terras raras e isótopos de $\mathrm{Nd}$ dessas rochas encaixantes e da soleira de diabásio demonstram que não houve troca de massa significativa entre a intrusão e as rochas sedimentares. Dessa forma, a transferência de calor entre a soleira e as rochas encaixantes ocorreu principalmente por difusão térmica (Santos et al. 2003).

Este trabalho apresenta as alterações minerais causadas nas rochas sedimentares da Formação Irati por uma soleira de diabásio de até treze metros. As ro- chas analisadas, que se encontram desde o contato com a intrusão até níveis sem influência térmica, foram divididas em zonas de metamorfismo de contato a partir do aparecimento de minerais-índice.

CONTEXTO GEOLÓGICO A Formação Irati é constituída, da base para o topo, pelos membros Taquaral e Assistência, considerados concordantes a partir da fauna de crustáceos (Barbosa \& Gomes 1958). O Membro Taquaral é formado por pelitos cinza-claros depositados sobre um conglomerado basal silexílico. Esse conglomerado demonstra uma importante discordância erosional, que marca o início da sedimentação da Formação Irati. O membro superior, Assistência, é caracterizado por folhelhos negros e calcários creme e escuros, contendo sílex e pirobetumes. Na região centro-sul da bacia, esse membro possui contato superior concordante com a Formação Serra Alta, e ao norte, o contato é concordante com a Formação Corumbataí (Padula 1968, Northfleet et al. 1969, Schneider et al. 1974).

No norte da Bacia do Paraná, a Formação Irati aflora entre as cidades de Alto Garças (MT), a oeste, e Montividiu (GO), a leste. Descrito tanto em afloramentos (Pedreira METAGO, Portelândia-GO), quanto em furos de sonda (Rodrigues inédito), o contato inferior é discordante sobre a Formação Aquidauana. A base da Formação Irati é caracterizada por níveis de conglomerado, sobrepostos por camadas de arenito e pelito de cor cinza esverdeada atribuídos ao Membro Taquaral, perfazendo cerca de 10 a $15 \mathrm{~m}$. O Membro Assistência, com espessura de cerca de $30 \mathrm{~m}$, é constituído pela intercalação de camadas decimétricas de folhelho cinza escuro a preto com dolomitos creme a cinza escuros,
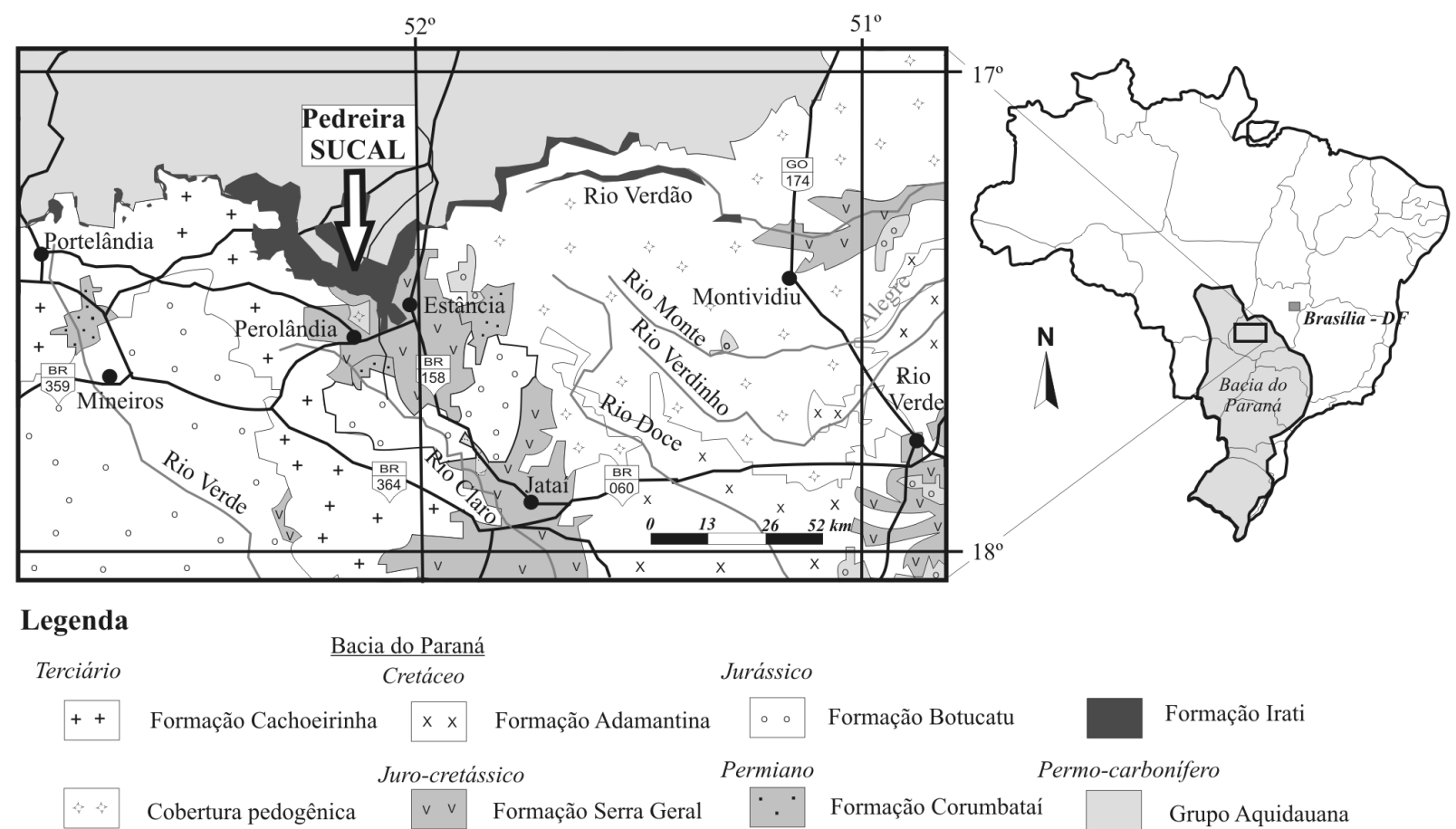

Figura 1 - Mapa geológico e de localização da área de estudo (Modificado de AGIM 2000). 
ocasionalmente silicificados e por vezes oolíticos (Costa et al. inédito). O contato com as unidades sobrepostas é identificado pelo aparecimento de níveis predominantemente terrígenos.

A Formação Irati na Pedreira SUCAL Na Pedreira SUCAL, localizada a $4 \mathrm{Km}$ a NE da cidade de Perolândia (GO), é extraído calcário dolomítico para corretivo de solo. Nas frentes de lavra dessa pedreira estão expostos pacotes de folhelhos e de rochas carbonáticas do Membro Assistência (Fig. 2), sobrepostos concordantemente por folhelhos, siltitos e arenitos da Formação Corumbataí.

Nas frentes de lavra I e II a seqüência sedimentar está intrudida por uma soleira de diabásio, que não ocor- re na Frente de Lavra III. As frentes de lavra II e III se situam, respectivamente, a cerca de $250 \mathrm{~m}$ a NE e $650 \mathrm{~m}$ a NW da Frente de Lavra I. Na Frente de Lavra I, onde estão expostos os contatos inferior e superior com a encaixante, a intrusão tem $13 \mathrm{~m}$ de espessura. Essa soleira diminui de espessura para NE, e já na Frente de Lavra II, apresenta somente $3 \mathrm{~m}$, desaparecendo para $\mathrm{N}$.

$\mathrm{Na}$ pedreira, a seqüência sedimentar foi subdividida, da base para o topo, nas fácies Carbonática Dolomítica-FCD, Pelítica Inferior-FPI, Carbonática Oolítica-FCO e Pelítica Superior - FPS (Anjos 2003).

A Fácies Carbonática Dolomítica é caracterizada por camadas de 5 a $10 \mathrm{~cm}$ de dololutito laminado cinza, intercaladas com níveis de aproximadamente $0,5 \mathrm{~cm}$

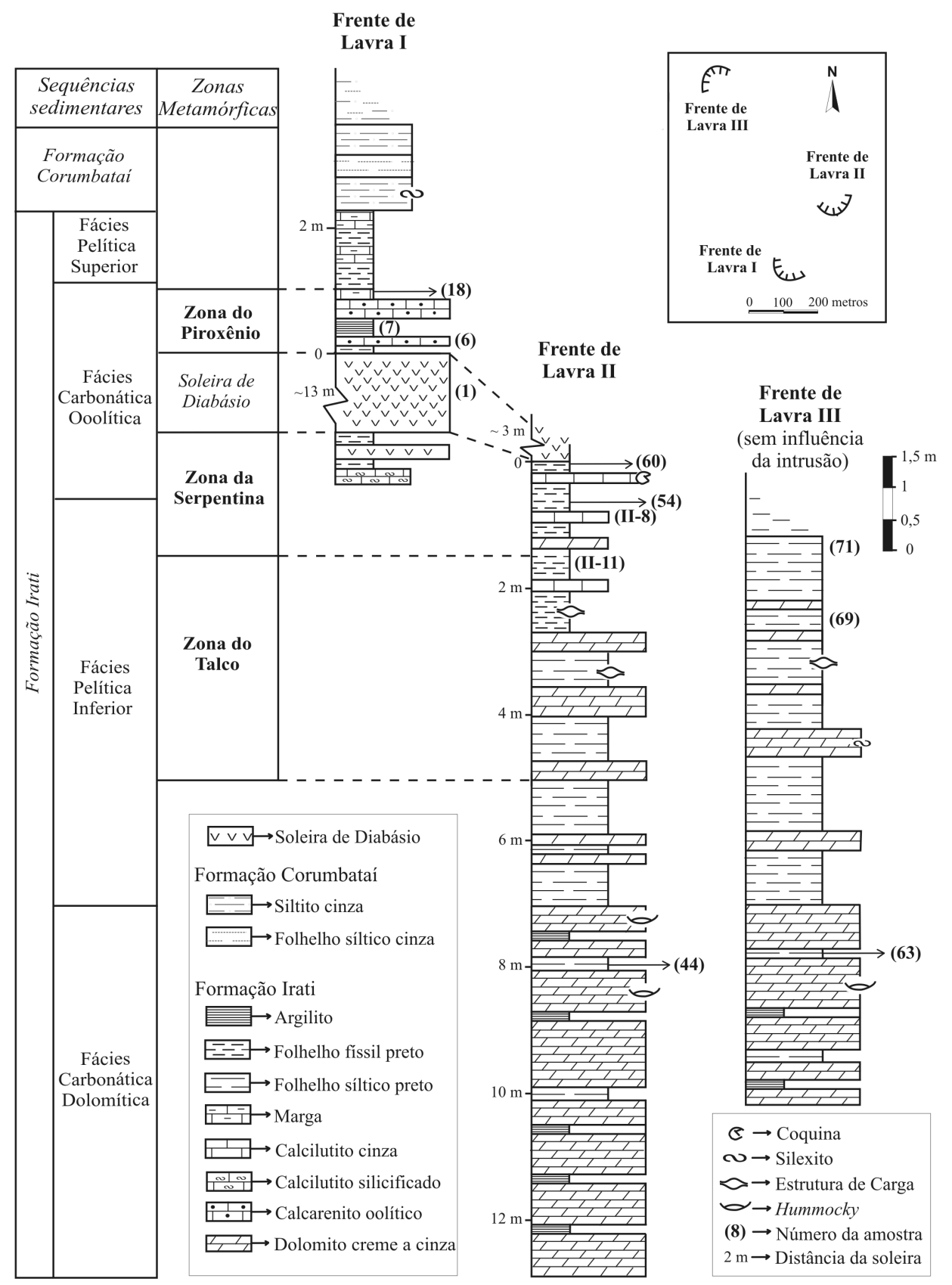

Figura 2 - Fácies sedimentares e zonas metamórficas das três frentes de lavra da Pedreira SUCAL (GO). 
de folhelho síltico cinza escuro. Exposta na base das frentes de lavra II e III, essa fácies tem o topo a mais de 6 metros abaixo da intrusão na Frente de Lavra II.

A Fácies Pelítica Inferior, com espessura de 6,5m, apresenta o predomínio de folhelho síltico cinza escuro na base e folhelho físsil preto na parte superior. Entre as camadas de 10 a $15 \mathrm{~cm}$ de folhelho ocorrem camadas de 2 a $5 \mathrm{~cm}$ de dololutito laminado cinza, argilito preto e concreções de silexito. Presente na porção superior da Frente de Lavra III, esta fácies está abaixo da soleira na Frente de Lavra II.

A Fácies Carbonática Oolítica é caracterizada por camadas de 10 a $25 \mathrm{~cm}$ de calcário oolítico, separadas por intercalações de argilito laminado, calcilutito, marga e folhelho, perfazendo cerca de $2 \mathrm{~m}$. É encontrada nas frentes de lavra I e II, intrudida pela soleira próximo à sua base.

Superposta à anterior, a Fácies Pelítica Superior é composta por um pacote de folhelho físsil preto intercalado com marga, cuja espessura não ultrapassa $2 \mathrm{~m}$. Ocorre apenas na Frente de Lavra I, sendo sobreposta pelos siltitos e arenitos da Formação Corumbataí.

MATERIAIS E MÉTODOS Para avaliar a influência térmica da soleira, foram analisadas amostras de rochas encaixantes nas frentes de Lavra I e II, tendo como controle a composição mineralógica das rochas sedimentares da Frente de Lavra III (não afetadas pela intrusão).

Amostras de pelitos e rochas carbonáticas foram coletadas em perfis nas três frentes de lavra, num total de 106 amostras. Selecionou-se ainda um nível de folhelho físsil preto rico em ostracodes (amostra: MP229, Almeida 2005), situado a norte da Frente de Lavra
II e posicionado na Fácies Carbonática Oolítica. Neste trabalho são apresentadas algumas análises de rochas das fácies Carbonática Dolomítica, Pelítica Inferior e Carbonática Oolítica (Tab. 1), em parte termalmente alteradas, mas para as quais será mantida a designação de rochas sedimentares. Feições metamórficas não foram identificadas na Fácies Pelítica Superior, correspondente à porção superior da Formação Irati, não sendo esta fácies detalhada nesse trabalho.

Para a determinação da composição mineralógica, todas as amostras foram submetidas a análises por difração de raios X. A partir dos resultados, foram selecionadas amostras para a caracterização da química mineral por microssonda eletrônica e de feições texturais por microscopia eletrônica de varredura.

A preparação das amostras para análise difratométrica seguiu as técnicas convencionais para análise de argilominerais, que consiste de tratamentos para separação da fração argila, solvatação por etilenoglicol e aquecimento. As análises foram realizadas no Laboratório de Raios X do Instituto de Geociências-UnB, em difratômetro Rigaku-D/MAX - $2 \mathrm{~A} / \mathrm{C}$, com tubo de cobre e filtro de Ni, operando com $40 \mathrm{kV}$ e $20 \mathrm{~mA}$. Para identificação e interpretação dos difratogramas foi utilizado o software JADE 3.0, com banco de dados ICDD (ICDD 1996). A definição de cada fase mineral, como constituinte maior, menor ou traço, foi obtida pela comparação das intensidades das suas reflexões características de distância interplanar $-d$. Para os argilominerais foram utilizadas as reflexões do pico em $d(001)$; para o quartzo, a calcita e a dolomita, foram utilizadas as reflexões $d$ em 4,26;

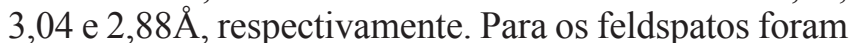
utilizadas as reflexões $d$ em torno de $3,19 \AA$.

Tabela 1 - Amostras tratadas neste trabalho. FCO: Fácies Carbonático Oolítica; FPI: Fácies Pelítica Inferior; FCD: Fácies Carbonática Dolomítica; DRX: Difração de Raios X; ME: Microssonda Eletrônica; MEV: Microscopia Eletrônica de Varredura.

\begin{tabular}{|c|c|c|c|c|c|}
\hline Localização & $\begin{array}{l}\text { Fácies } \\
\text { Sedim. }\end{array}$ & $\begin{array}{c}\text { Zona } \\
\text { Metamórf. }\end{array}$ & Amostra & Caracterização macroscópica & Análises \\
\hline \multirow{3}{*}{ Frente I } & \multirow{5}{*}{ FCO } & \multirow{3}{*}{$\begin{array}{l}\text { Zona do } \\
\text { Piroxênio }\end{array}$} & $(18)$ & Marga cinza clara & DRX, ME, MEV \\
\hline & & & (7) & $\begin{array}{l}\text { Argilito laminado cinza esverdeado } \\
\text { com ossículos }\end{array}$ & DRX, ME, MEV \\
\hline & & & (6) & $\begin{array}{l}\text { Calcarenito oolítico silicificado } \\
\text { com ossículos }\end{array}$ & $\mathrm{DRX}, \mathrm{ME}$ \\
\hline \multirow{6}{*}{ Frente II } & & $\begin{array}{c}\text { Zona da } \\
\text { Serpentina }\end{array}$ & $(60)$ & Folhelhos físsil preto & DRX \\
\hline & & Zona do Talco & $\begin{array}{c}\text { (MP-229) } \\
\mathrm{N} \text { da Frente II }\end{array}$ & $\begin{array}{l}\text { Folhelho físsil preto com ostracodes } \\
\text { e ossículos. }\end{array}$ & $\mathrm{DRX}, \mathrm{ME}$ \\
\hline & \multirow{3}{*}{ FPI } & \multirow{2}{*}{$\begin{array}{c}\text { Zona da } \\
\text { Serpentina }\end{array}$} & $(54)$ & Folhelho físsil preto & DRX \\
\hline & & & (II-8) & Calcilutito preto & DRX \\
\hline & & Zona do Talco & (II-11) & $\begin{array}{l}\text { Folhelho síltico preto com ossículos } \\
\text { e pirita }\end{array}$ & DRX \\
\hline & FCD & \multirow{4}{*}{-} & $(44)$ & Folhelho síltico cinza escuro & DRX \\
\hline \multirow{3}{*}{ Frente III } & FPI & & $(71)$ & Folhelho síltico cinza escuro & DRX \\
\hline & & & (69) & Folhelho síltico cinza escuro & DRX \\
\hline & FCD & & $(63)$ & Folhelho síltico cinza & DRX \\
\hline Frente I & - & Intrusão ígnea & $(60)$ & Diabásio amigdaloidal & DRX, ME \\
\hline
\end{tabular}


Por microssonda eletrônica foram analisados: calcarenito oolítico, argilito, marga e diabásio, estando as rochas sedimentares à distâncias inferiores a $1 \mathrm{~m}$ da intrusão. As análises foram feitas no Laboratório de Microssonda do IG-UnB, em Microssonda CAMECA/Camebax, operando com $15 \mathrm{kV}$, feixe de $5-10 \AA$, tempo de contagem de 10-15s/elemento. A partir das análises, adquiridas em porcentagem de óxidos, foram obtidas as fórmulas estruturais, recalculando-se os valores percentuais em peso de óxidos para a base de 14 e 22 átomos de oxigênio respectivamente, para os filossilicatos do tipo 1:1 e 2:1. Para os piroxênios, os valores percentuais em peso de óxidos foram recalculados para a base de 6 átomos de oxigênio, e de 32 átomos de oxigênio para o plagioclásio.

As análises por microscopia eletrônica de varredura foram realizadas em argilito e marga, no Laboratório de Solos do Departamento de Apoio e Controle Técnico de FURNAS - Centrais Elétricas S.A, em Aparecida de Goiânia (GO). As imagens foram obtidas utilizando conjuntamente os detectores de elétrons secundários (SE) e de elétrons retroespalhados (QBSE). A microanálise foi realizada utilizando-se o espectrômetro por energia dispersiva de raios X (EDS).

\section{COMPOSIÇÃO MINERAL A DIFERENTES DIS-} TÂNCIAS DA SOLEIRA A comparação da associação mineral das rochas sem influência da soleira (Frente de Lavra III) com as rochas próximas à intrusão (Frentes de Lavra I e II) evidenciou zonas de metamorfismo de contato, a partir do aparecimento de mineraisíndices (Fig. 2). As zonas metamórficas identificadas respectivamente em direção à soleira foram: Zona do Talco, Zona da Serpentina e Zona do Piroxênio.

Devido a granulometria fina das rochas (fração silte-argila), a caracterização mineralógica foi feita a partir de dados de difração de raios X (Figs. 3 e 4), microssonda eletrônica (Tabs. 2, 3, 4 e Fig. 5) e microscopia eletrônica de varredura (Fig. 6).
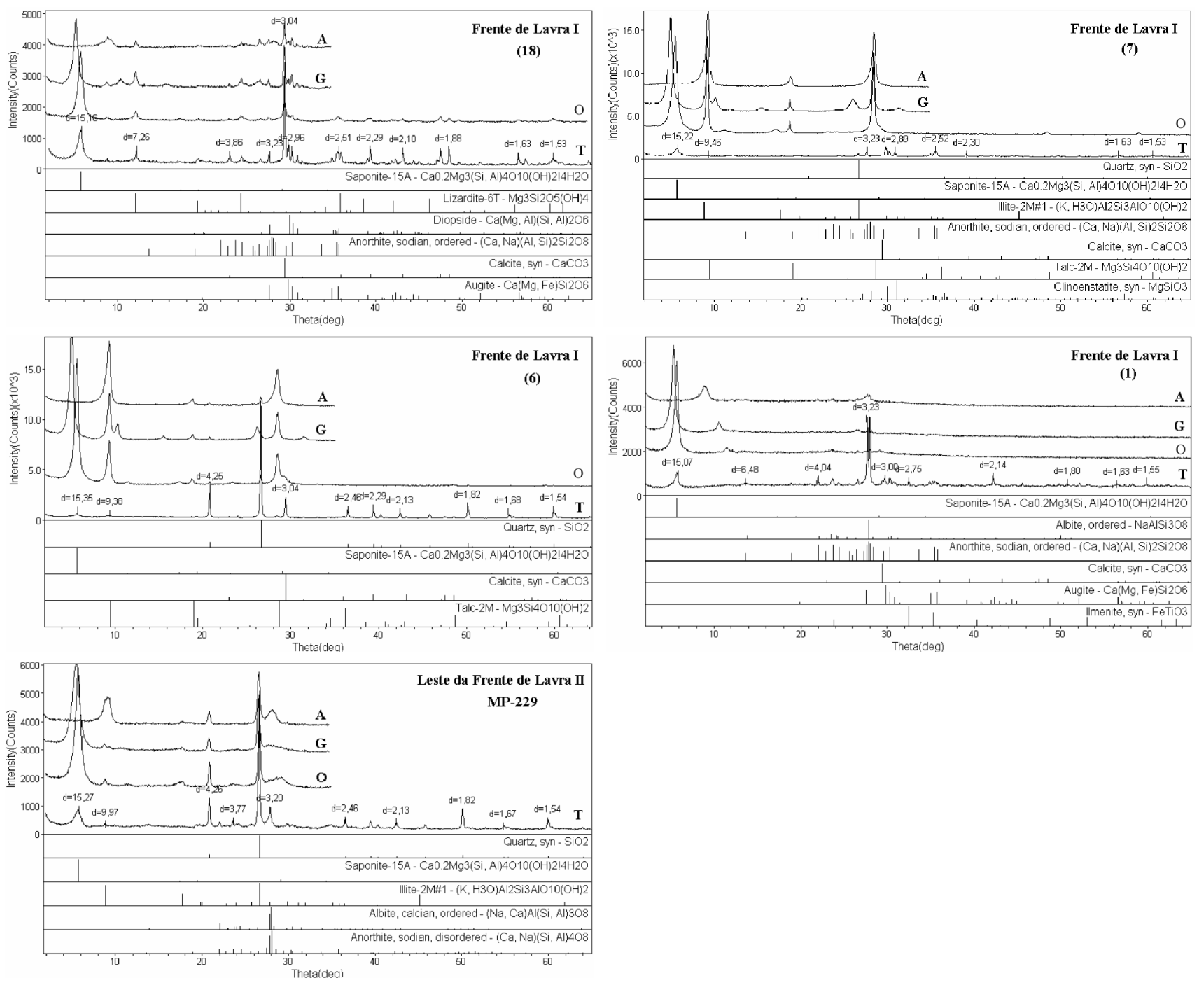

Figura 3 - Difratogramas de raios $X$ das amostras da Frente de Lavra I e do folhelho fissil ostracoidal (MP-229). T: amostra total, $O$ : fração argila orientada, $G$ : fração argila solvatada com etileno-glicol, $A$ : fração argila aquecida à $490^{\circ} \mathrm{C}$ por 3,5 horas. 

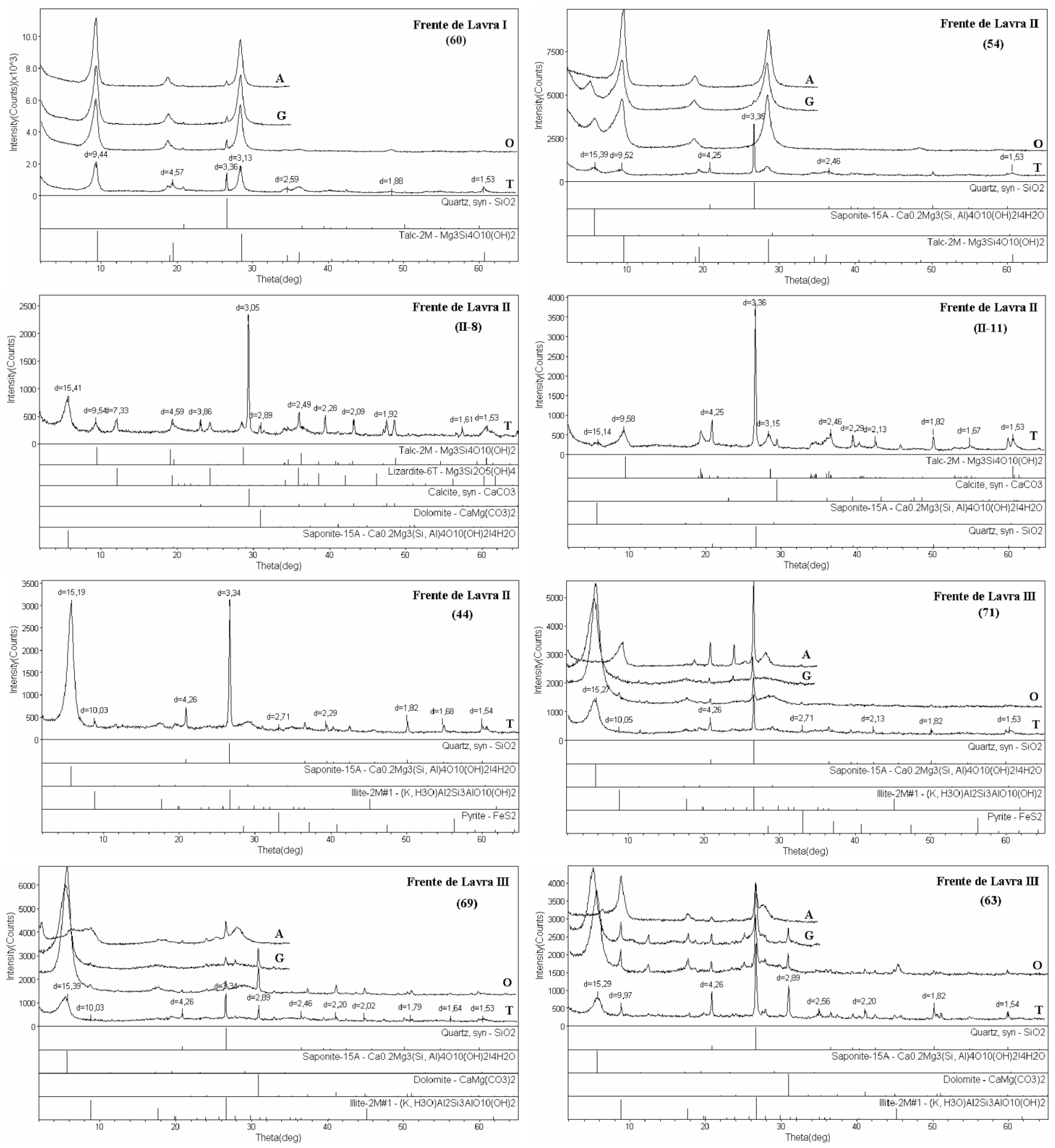

Figura 4 - Difratogramas de raios X das amostras das frentes de lavra II e III. T: amostra total, O: fração argila orientada, G: fração argila solvatada com etileno-glicol, $A$ : fração argila aquecida à $490^{\circ} \mathrm{C}$ por 3,5 horas.

Rochas não alteradas pela intrusão As rochas isentas da influência do halo térmico situam-se na Frente de Lavra III e a partir de 5,5m abaixo da soleira na Frente de Lavra II, posicionadas nas fácies Carbonática Dolomítica e Pelítica Inferior.

Os pelitos são formados principalmente por saponita, uma espécie de esmectita trioctaédrica magnesiana, além de quartzo, como constituinte maior ou menor, e ilita e dolomita como constituintes menores ou traços. A zeólita e a caolinita são constituintes-traço na base da frente de Lavra II.

As rochas carbonáticas são dolomitos, tendo como constituintes menores ou traços o quartzo, a calcita, a ilita, o plagioclásio e a saponita.

A pirita é comum, particularmente como cristais euédricos maiores que $1 \mathrm{~mm}$. A sepiolita ocorre como mineral traço nas rochas carbonáticas e a gipsita está presente em alguns níveis de pelitos, como produto de alteração intempérica. 
Tabela 2 - Composição em percentagem de óxidos e fórmula estrutural da saponita, Fe-saponita e talco.

\begin{tabular}{|c|c|c|c|c|c|c|c|c|c|c|c|c|c|c|c|c|c|c|c|c|}
\hline \multirow{3}{*}{$\begin{array}{l}\text { Óxidos \% } \\
\mathrm{SiO}_{2} \\
\end{array}$} & \multicolumn{3}{|c|}{ Saponita } & \multicolumn{7}{|c|}{$\mathrm{Fe}$ - Saponita } & \multicolumn{10}{|c|}{ Talco } \\
\hline & \multirow{2}{*}{\begin{tabular}{|l}
$(18)$ \\
34,9 \\
\end{tabular}} & \multicolumn{2}{|c|}{ MP-229 } & \multicolumn{7}{|c|}{$(1)$} & \multicolumn{2}{|c|}{ (7) } & \multicolumn{2}{|c|}{$(18)$} & \multicolumn{6}{|c|}{ (6) } \\
\hline & & 41,5 & 48,8 & 37,1 & 41,9 & 41,4 & 41,6 & 38,0 & 41,1 & 44,4 & 51,6 & 55,8 & 44,6 & 44,7 & 54,0 & 57,1 & 60,3 & 62,0 & 59,4 & 58,5 \\
\hline $\mathrm{TiO}_{2}$ & 0,1 & 0,3 & 0,1 & 0,1 & 0,1 & 0,0 & 0,4 & 0,5 & 0,3 & 0,6 & 0,0 & 0,0 & 0,1 & 0,1 & 0,0 & 0,0 & 0,0 & 0,0 & 0,0 & 0,0 \\
\hline $\mathrm{Al}_{2} \mathrm{O}_{3}$ & 4,4 & 4,3 & 4,6 & 5,8 & 7,6 & 7,4 & 5,0 & 5,2 & 6,3 & 5,6 & 1,6 & 1,4 & 2,5 & 5,3 & 0,3 & 0,5 & 0,4 & 1,5 & 0,6 & 0,4 \\
\hline $\mathrm{FeO}$ & 6,7 & 4,3 & 5,0 & 21,4 & 22,5 & 22,4 & 16,9 & 19,1 & 9,8 & 20,1 & 4,0 & 4,5 & 4,4 & 4,3 & 5,4 & 4,0 & 3,9 & 4,6 & 5,0 & 5,9 \\
\hline $\mathrm{MgO}$ & 15,1 & 15,7 & 20,4 & 7,6 & 10,9 & 10,7 & 10,5 & 8,2 & 17,9 & 9,8 & 24,0 & 25,0 & 23,8 & 25,2 & 22,3 & 26,1 & 27,6 & 28,3 & 25,9 & 24,5 \\
\hline $\mathrm{MnO}$ & 0,1 & 0,1 & 0,1 & 0,0 & 0,0 & 0,0 & 0,4 & 2,9 & 0,4 & 2,5 & 0,0 & 0,0 & 0,4 & 0,4 & 0,0 & 0,0 & 0,0 & 0,1 & 0,0 & 0,1 \\
\hline $\mathrm{CaO}$ & 3,2 & 1,0 & 0,4 & 1,5 & 1,4 & 1,1 & 1,8 & 2,0 & 2,3 & 1,8 & 1,4 & 0,6 & 1,3 & 1,4 & 0,3 & 0,2 & 0,3 & 0,3 & 0,4 & 0,2 \\
\hline $\mathrm{Na}_{2} \mathrm{O}$ & 0,5 & 0,3 & 0,4 & 0,0 & 0,2 & 0,3 & 0,1 & 0,2 & 0,4 & 0,3 & 0,2 & 0,1 & 0,1 & 0,1 & 0,1 & 0,2 & 0,2 & 0,5 & 0,4 & 0,4 \\
\hline $\mathrm{K}_{2} \mathrm{O}$ & 0,4 & 0,4 & 0,3 & 0,9 & 1,0 & 0,8 & 0,2 & 0,3 & 0,1 & 0,2 & 0,1 & 0,1 & 0,1 & 0,1 & 0,2 & 0,2 & 0,1 & 0,3 & 0,4 & 0,3 \\
\hline Soma & 65,4 & 67,9 & 80,1 & 74,4 & 85,6 & 84,1 & 76,9 & 76,4 & 78,6 & 85,3 & 82,9 & 87,5 & 77,3 & 81,6 & 82,8 & 88,2 & 92,9 & 97,5 & 92,0 & 90,2 \\
\hline
\end{tabular}

Fórm. Estrut.

\begin{tabular}{l|c|c|c|c|c|c|c|c|c|c|c|c|c|c|c|c|c|c|c|c}
\hline $\mathrm{Si}$ & 7,0 & 7,5 & 7,5 & 7,0 & 6,8 & 6,9 & 7,3 & 7,0 & 6,9 & 7,2 & 7,7 & 7,9 & 7,3 & 6,9 & 8,1 & 8,0 & 8,0 & 7,9 & 8,0 & 8,0 \\
\hline $\mathrm{Al}_{\mathrm{IV}}$ & 1,0 & 0,5 & 0,5 & 1,0 & 1,2 & 1,1 & 0,7 & 1,0 & 1,1 & 0,8 & 0,3 & 0,1 & 0,5 & 1,0 & & 0,0 & 0,0 & 0,1 & 0,0 & 0,0 \\
\hline $\mathrm{Fe}_{\mathrm{IV}}$ & & & & & & & & & & & & & 0,2 & 0,1 & & & & & & \\
\hline $\mathrm{Al}_{\mathrm{VI}}$ & 0,0 & 0,5 & 0,3 & 0,3 & 0,3 & 0,3 & 0,3 & 0,1 & 0,1 & 0,3 & 0,0 & 0,1 & 0,0 & 0,0 & 0,1 & 0,0 & 0,0 & 0,1 & 0,1 & 0,1 \\
\hline $\mathrm{Ti}$ & 0,0 & 0,0 & 0,0 & 0,0 & 0,0 & 0,0 & 0,1 & 0,1 & 0,0 & 0,1 & 0,0 & 0,0 & 0,0 & 0,0 & 0,0 & 0,0 & 0,0 & 0,0 & 0,0 & 0,0 \\
\hline $\mathrm{Fe}_{\mathrm{VI}}$ & 1,1 & 0,6 & 0,6 & 3,4 & 3,1 & 3,1 & 2,5 & 2,9 & 1,4 & 2,7 & 0,5 & 0,5 & 0,4 & 0,4 & 0,7 & 0,5 & 0,4 & 0,5 & 0,6 & 0,7 \\
\hline $\mathrm{Mg}$ & 4,5 & 4,3 & 4,7 & 2,2 & 2,7 & 2,6 & 2,8 & 2,3 & 4,4 & 2,4 & 5,4 & 5,2 & 5,8 & 5,8 & 5,0 & 5,4 & 5,4 & 5,3 & 5,2 & 5,0 \\
\hline $\mathrm{Mn}$ & 0,0 & 0,0 & 0,0 & 0,0 & 0,0 & 0,0 & 0,1 & 0,5 & 0,1 & 0,3 & 0,0 & 0,0 & 0,1 & 0,1 & 0,0 & 0,0 & 0,0 & 0,0 & 0,0 & 0,0 \\
\hline $\mathrm{Suma}$ Octae. & 5,6 & 5,4 & 5,6 & 5,9 & 6,1 & 6,0 & 5,8 & 5,9 & 6,0 & 5,8 & 5,9 & 5,8 & 6,3 & 6,3 & 5,8 & 5,9 & 5,8 & 5,9 & 5,9 & 5,8 \\
\hline $\mathrm{Ca}$ & 0,7 & 0,2 & 0,1 & 0,3 & 0,2 & 0,2 & 0,3 & 0,4 & 0,4 & 0,3 & 0,2 & 0,1 & 0,2 & 0,2 & 0,0 & 0,0 & 0,0 & 0,0 & 0,1 & 0,0 \\
\hline $\mathrm{Na}$ & 0,2 & 0,1 & 0,1 & 0,0 & 0,1 & 0,1 & 0,0 & 0,1 & 0,1 & 0,1 & 0,1 & 0,0 & 0,0 & 0,0 & 0,0 & 0,1 & 0,1 & 0,1 & 0,1 & 0,1 \\
\hline $\mathrm{K}$ & 0,1 & 0,1 & 0,1 & 0,2 & 0,2 & 0,2 & 0,1 & 0,1 & 0,0 & 0,0 & 0,0 & 0,0 & 0,0 & 0,0 & 0,0 & 0,0 & 0,0 & 0,0 & 0,1 & 0,1 \\
\hline Soma de Álcalis & 1,0 & 0,4 & 0,3 & 0,5 & 0,5 & 0,5 & 0,4 & 0,6 & 0,5 & 0,4 & 0,3 & 0,1 & 0,2 & 0,2 & 0,1 & 0,1 & 0,1 & 0,1 & 0,3 & 0,2 \\
\hline
\end{tabular}

Rochas alteradas pela intrusão A influência da soleira sobre os dolomitos e pelitos é assinalada pelo aparecimento e desaparecimento de minerais. Desde as porções mais afastadas em direção ao contato com a rocha intrusiva, ocorrem as zonas do talco, da serpentina e do piroxênio, distribuídas de forma distinta acima e abaixo da soleira.

De maneira geral, as análises petrográficas mostram que as rochas do halo térmico preservam as feições sedimentares, como laminação, rede de estilólitos e veios preenchidos por calcita, quartzo e matéria orgânica, estando a última carbonizada nas proximidades da soleira (Anjos et al. 2003). Não foram observadas feições proeminentes de hidrotermalismo, relacionadas aos efeitos termais provocados pela intrusão da soleira.

ZONA DO TALCO Esta zona, situada entre 5,5 e 1,5 metros abaixo da soleira, é caracterizada pela presença do talco nas rochas da Fácies Pelítica Inferior. Associado à saponita e ao quartzo, o talco adentra a zona da serpentina e persiste até o contato com a intrusão. Outro mineral que aparece nessa zona é a calcita, que assim como o talco, mostra tendência do aumento de seu conteúdo em direção à soleira, concomitantemente com a diminuição da dolomita.

No nível de folhelho físsil preto ostracoidal, que se situa a $\mathrm{N}$ da Frente de Lavra II, as carapaças de ostracodes dispersas na matriz argilosa tem composição de plagioclásio (Tab. 4, Fig. 5). A matriz é constituída essencialmente por esmectita, tendo quartzo e plagioclásio como constituintes menores e a ilita como constituinte traço. Na fração argila, além destes, é identificado também o talco como constituinte traço.

ZONA DA SERPENTINA Situada desde 1,5m abaixo até o contato inferior com a intrusão, a zona da serpentina é assinalada pela presença da lizardita nas rochas carbonáticas do topo da Fácies Pelítica Inferior e da Fácies Carbonática Oolítica.

Nesta zona, as rochas carbonáticas são dolomitos 
Tabela 3 - Composição em percentagem de óxidos e fórmula estrutural do piroxênio.

\begin{tabular}{|c|c|c|c|c|c|c|c|c|c|c|c|c|}
\hline \multirow{3}{*}{$\frac{\text { Óxidos \% }}{\mathrm{SiO}_{2}}$} & \multicolumn{12}{|c|}{ Piroxênio } \\
\hline & \multicolumn{4}{|c|}{ (7) } & \multicolumn{4}{|c|}{ (18) } & \multicolumn{4}{|c|}{ (1) } \\
\hline & 56,3 & 56,9 & 58,9 & 58,7 & 58,0 & 53,9 & 50,5 & 50,4 & 47,5 & 47,1 & 49,1 & 48,8 \\
\hline $\mathrm{TiO}_{2}$ & 0,0 & 0,1 & 0,0 & 0,1 & 0,0 & 2,4 & 0,2 & 0,1 & 2,5 & 2,2 & 1,5 & 1,9 \\
\hline $\mathrm{Al}_{2} \mathrm{O}_{3}$ & 1,7 & 1,8 & 1,3 & 3,0 & 1,9 & 2,1 & 1,2 & 1,1 & 4,0 & 4,5 & 3,6 & 3,9 \\
\hline FeO & 4,7 & 5,1 & 4,4 & 6,5 & 5,4 & 5,5 & 3,8 & 2,2 & 15,1 & 15,2 & 12,1 & 12,3 \\
\hline $\mathrm{Cr}_{2} \mathrm{O}_{3}$ & 0,0 & 0,0 & 0,0 & 0,0 & 0,0 & 0,0 & 0,0 & 0,0 & 0,0 & 0,1 & 0,1 & 0,2 \\
\hline $\mathrm{MgO}$ & 26,8 & 27,4 & 28,0 & 27,6 & 27,3 & 25,4 & 17,3 & 20,9 & 13,6 & 12,8 & 13,7 & 14,1 \\
\hline $\mathrm{MnO}$ & 0,1 & 0,0 & 0,0 & 0,0 & 0,0 & 0,0 & 0,3 & 0,3 & 0,3 & 0,3 & 0,3 & 0,2 \\
\hline $\mathrm{NiO}$ & 0,0 & 0,0 & 0,0 & 0,1 & 0,0 & 0,0 & 0,0 & 0,0 & 0,0 & 0,0 & 0,0 & 0,0 \\
\hline $\mathrm{CaO}$ & 0,4 & 0,3 & 0,3 & 0,8 & 0,5 & 2,1 & 16,8 & 14,9 & 16,2 & 16,1 & 18,2 & 18,3 \\
\hline $\mathrm{NaO}$ & 0,2 & 0,2 & 0,1 & 0,2 & 0,3 & 0,1 & 0,2 & 0,2 & 0,3 & 0,3 & 0,3 & 0,4 \\
\hline $\mathrm{K}_{2} \mathrm{O}$ & 0,1 & 0,1 & 0,2 & 0,4 & 0,3 & 0,1 & 0,2 & 0,2 & 0,0 & 0,1 & 0,1 & 0,0 \\
\hline Soma & 90,4 & 91,9 & 93,2 & 97,2 & 93,8 & 91,7 & 90,5 & 90,2 & 99,4 & 98,7 & 99,0 & 100,0 \\
\hline \multicolumn{13}{|c|}{ Fórmula Estrutural } \\
\hline $\mathrm{Si}$ & 2,1 & 2,1 & 2,1 & 2,1 & 2,1 & 2,0 & 2,0 & 2,0 & 1,8 & 1,8 & 1,9 & 1,8 \\
\hline $\mathrm{Al}_{\mathrm{IV}}$ & & & & & & & & 0,0 & 0,2 & 0,2 & 0,1 & 0,2 \\
\hline Soma do Tetra. & 2,1 & 2,1 & 2,1 & 2,1 & 2,1 & 2,0 & 2,0 & 2,0 & 2,0 & 2,0 & 2,0 & 2,0 \\
\hline $\mathrm{Al}_{\mathrm{VI}}$ & 0,1 & 0,1 & 0,1 & 0,1 & 0,1 & 0,1 & 0,1 & 0,0 & & 0,0 & 0,0 & 0,0 \\
\hline $\mathrm{Ti}$ & 0,0 & 0,0 & 0,0 & 0,0 & 0,0 & 0,1 & 0,0 & 0,0 & 0,1 & 0,1 & 0,0 & 0,1 \\
\hline $\mathrm{Fe}$ & 0,1 & 0,2 & 0,1 & 0,2 & 0,2 & 0,2 & 0,1 & 0,1 & 0,5 & 0,5 & 0,4 & 0,4 \\
\hline $\mathrm{Cr}$ & 0,0 & 0,0 & 0,0 & 0,0 & 0,0 & 0,0 & 0,0 & 0,0 & 0,0 & 0,0 & 0,0 & 0,0 \\
\hline $\mathrm{Mg}$ & 1,5 & 1,5 & 1,5 & 1,4 & 1,5 & 1,4 & 1,0 & 1,2 & 0,8 & 0,7 & 0,8 & 0,8 \\
\hline $\mathrm{Ni}$ & 0,0 & 0,0 & 0,0 & 0,0 & 0,0 & 0,0 & 0,0 & 0,0 & 0,0 & 0,0 & 0,0 & 0,0 \\
\hline $\mathrm{Mn}$ & 0,0 & 0,0 & 0,0 & 0,0 & 0,0 & 0,0 & 0,0 & 0,0 & 0,0 & 0,0 & 0,0 & 0,0 \\
\hline $\mathrm{Ca}$ & 0,0 & 0,0 & 0,0 & 0,0 & 0,0 & 0,1 & 0,7 & 0,6 & 0,7 & 0,7 & 0,7 & 0,7 \\
\hline $\mathrm{Na}$ & 0,0 & 0,0 & 0,0 & 0,0 & 0,0 & 0,0 & 0,0 & 0,0 & 0,0 & 0,0 & 0,0 & 0,0 \\
\hline $\mathrm{K}$ & 0,0 & 0,0 & 0,0 & 0,0 & 0,0 & 0,0 & 0,0 & 0,0 & 0,0 & 0,0 & 0,0 & 0,0 \\
\hline Soma do Octa. & 1,7 & 1,8 & 1,7 & 1,8 & 1,8 & 1,9 & 2,0 & 2,0 & 2,0 & 2,0 & 2,0 & 2,0 \\
\hline
\end{tabular}

calcíferos passando a calcários dolomíticos e, a partir de $0,3 \mathrm{~m}$ até o contato com a intrusão, são calcários. Por vezes argilosas, estas rochas contêm como constituintes menores ou traços, além da lizardita, o talco e a esmectita.

Intercalados nas rochas carbonáticas, os pelitos - representados por folhelho físsil preto, folhelho síltico cinza escuro e argilito preto - não contêm serpentina. São compostos por saponita como constituinte maior, quartzo e talco como constituintes maiores a traços e ilita como constituinte traço. $\mathrm{O}$ folhelho físsil preto no contato com a soleira é composto apenas por talco como constituinte maior e quartzo como constituinte menor.

ZONA DO PIROXÊNIO Posicionada a até $1,0 \mathrm{~m}$ acima do contato superior com a intrusão, esta zona é caracterizada pela ocorrência do piroxênio. Está restrita à Fácies Carbonática Oolítica, constituída por uma intercalação de calcarenito oolítico com argilito, folhelho e marga. A calcita é o único carbonato presente nas rochas carbonáticas e na marga.

O piroxênio ocorre como microcristais euédri-
Tabela 4 - Composição em percentagem de óxidos do plagioclásio.

\begin{tabular}{|c|c|c|c|c|c|c|}
\hline \multirow{3}{*}{$\begin{array}{l}\text { \% de } \\
\text { Óxidos } \\
\mathrm{SiO}_{2} \\
\end{array}$} & \multicolumn{6}{|c|}{ Plagoclásio } \\
\hline & \multicolumn{6}{|c|}{ МP-229 } \\
\hline & 58.32 & 67.843 & 66.204 & 65.207 & 57.132 & 67.335 \\
\hline $\mathrm{TiO}_{2}$ & 0 & 0.011 & 0.032 & 0.008 & 0.04 & 0.008 \\
\hline $\mathrm{Al}_{2} \mathrm{O}_{3}$ & 14.577 & 18.646 & 18.448 & 17.872 & 16.112 & 18.209 \\
\hline $\mathrm{FeO}$ & 0.238 & 0.034 & 0.055 & 0.058 & 0.419 & 0.083 \\
\hline MgO & 0.097 & 0.004 & 0.022 & 0.019 & 0.394 & 0.036 \\
\hline $\mathrm{MnO}$ & 0 & 0 & 0 & 0 & 0 & 0 \\
\hline $\mathrm{CaO}$ & 0.479 & 0.261 & 0.244 & 0.249 & 0.802 & 0.27 \\
\hline $\mathrm{NaO}$ & 7.095 & 8.679 & 8.73 & 8.544 & 7.54 & 9.088 \\
\hline $\mathrm{K}_{2} \mathrm{O}$ & 1.025 & 3.611 & 3.222 & 2.745 & 1.599 & 2.77 \\
\hline Soma & 81.831 & 99.089 & 96.957 & 94.702 & 84.038 & 97.799 \\
\hline
\end{tabular}




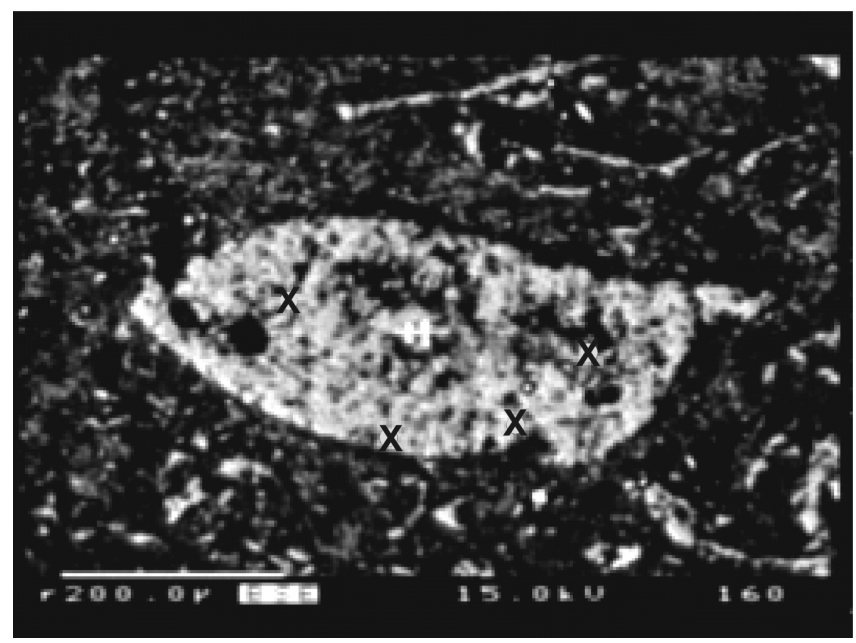

Figura 5 - Carapaça de ostracode do folhelho fissil preto ostracoidal (MP-229) com composição de plagioclásio. Imagem de microssonda eletrônica em lâmina polida metalizada. X: pontos analisados por microssonda eletrônica.

cos, com tamanho médio de $5 \mu \mathrm{m}$, na marga e no argilito (Fig. 6). Nessas rochas, a saponita é constituinte maior, sendo a serpentina e o talco constituintes menores na marga e no argilito respectivamente. Esses minerais ocorrem também nas rochas carbonáticas e nos folhelhos negros, nos quais o piroxênio é ausente. Os pelitos dessa zona apresentam carapaças de ostracodes com composição de plagioclásio. Na matriz do argilito ocorrem também raras lamelas de mica dioctaédrica, interpretadas como detríticas.

As análises dos filossilicatos por microssonda eletrônica, plotadas no diagrama $\mathrm{M}^{+}-4 \mathrm{Si}-3 \mathrm{R}^{2+}$ (Bouchet et al. 2000), situam-se principalmente nos campos da saponita, do talco e próximo ao campo da muscovita (Fig. 7). Os minerais posicionados no campo da ilita dioctaédrica pertencem ao argilito, que contém ainda saponita, serpentina e talco, mas destaca-se pelo seu conteúdo em piroxênio.

As análises por microssonda eletrônica dos piroxênios da marga e do argilito mostram que estes possuem uma composição predominantemente magnesiana. No diagrama Wo-En-Fs (Morinoto et al. 1988), os piroxênios do argilito concentram-se no campo da enstatita, enquanto os piroxênios da marga distribuem-se nos campos da enstatita, pigeonita e augita de forma linear, variando os componentes En e Wo (Fig. 8). O piroxênio do argilito tem uma composição próxima a enstatita. $\mathrm{Na}$ marga, além de piroxênios com composição de enstatita, as análises mostram que alguns cristais apresentam uma quantidade considerável de $\mathrm{Ca}^{2+}$, aproximando-se da composição do diopsídio (Tab. 3).

Intrusão Ígnea A soleira de diabásio, na Frente de Lavra I, onde estão expostos os contatos inferior e superior com a encaixante, tem espessura de cerca de $13 \mathrm{~m}$. $\mathrm{Na}$ Frente de Lavra II, que fica a $250 \mathrm{~m}$ a NE da anterior,

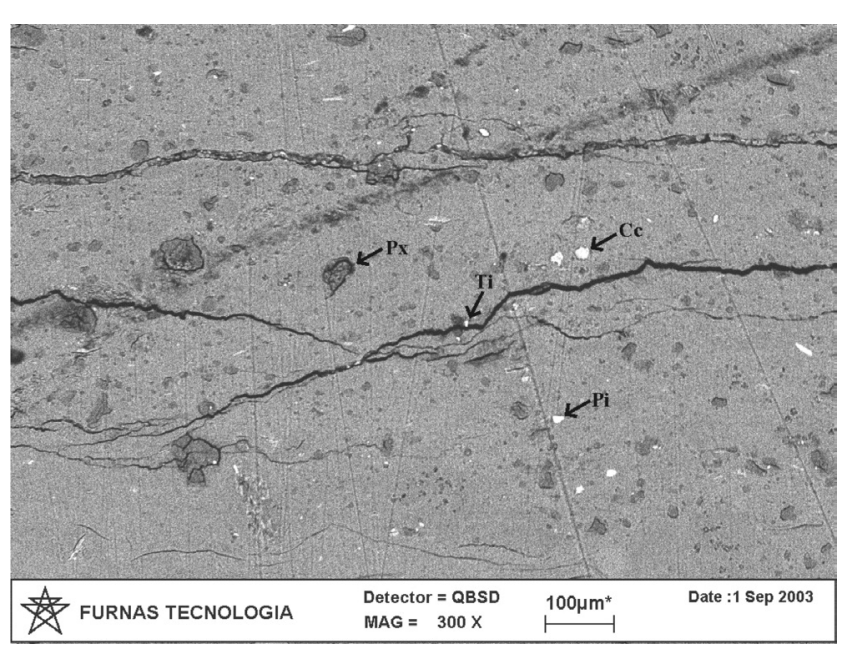

Figura 6 - Matriz do argilito (7) com microcristais de piroxênio (Px), além de calcita (Cc), pirita (Pi) e titanita (Ti). Imagem de microscopia eletrônica de varredura em lâmina polida metalizada.

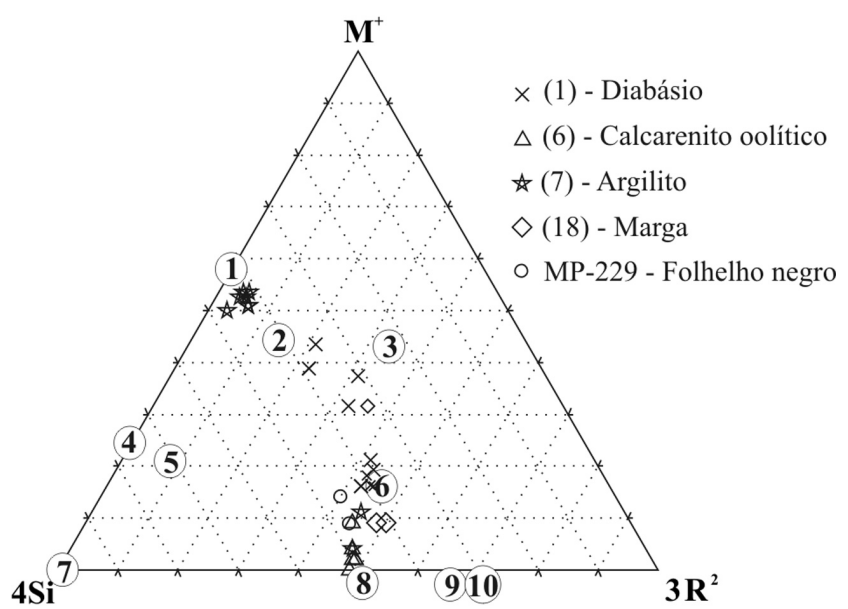

Figura 7 - Projeção da composição química de filossilicatos no diagrama $\mathrm{M}^{+}-4 \mathrm{Si}-3 \mathrm{R}^{2+}$ (Bouchet et al. 2000). As análises químicas foram obtidas por microssonda eletrônica. Legenda - 1: muscovita; 2: celadonita; 3: flogopita; 4: beideleita; 5: montmorilonita; 6: saponita; 7: caolinita, pirofilita; 8: talco; 9: lizardita; 10: clorita.

a espessura passa a ser de apenas $3 \mathrm{~m}$, diminuindo para NE até desaparecer.

O diabásio possui textura porfirítica, com fenocristais de plagioclásio, piroxênio e olivina dispersos em matriz fanerítica fina. A matriz é composta por plagioclásio, augita e calcita, além de ilmenita e pirita como minerais acessórios. Nas partes mais próximas da encaixante, o diabásio encontra-se quase totalmente alterado para argilominerais, desaparecendo os fenocristais característicos. 
As análises por microssonda eletrônica confirmaram a composiçao augítica do piroxênio, e reveleram que as amigdalas do diabásio são preenchidas total ou parcialmente por calcita, talco, Fe-saponita e minerais interestratificados. Os filossilicatos ocorrem também como produtos de alteração na matriz.

DISCUSSÃO As análises por difração de raios $\mathrm{X}$ e microssonda eletrônica mostram um predomínio de minerais magnesianos, tanto nas rochas sedimentares pelíticas (saponita) e carbonáticas (dolomita) fora do halo térmico quanto em seus equivalentes metamórficos (talco, lizardita e piroxênio).

Rochas sedimentares formadas predominantemente por saponita possuem uma gênese vinculada à queda de cinzas vulcânicas em bacias salinas, ou ainda, a uma fonte formada por rochas básicas a ultrabásicas (Post 1984, Chamley 1989, Akbulut \& Kadir 2003, Setti et al. 2004, Meunier 2003, Ehrmann et al. 2005, Yalçin \& Bozkaya 2006).

Em auréolas de contato, o comportamento de argilominerais magnesianos sedimentares ainda não é bem conhecido. Em pelitos compostos por argilominerais aluminosos, a quantidade de ilita aumenta e os minerais interestratificados tornam-se mais ordenados em direção à intrusão (April 1980, Nadeau \& Reynolds 1981, Vergo \& April 1982, Bühmann 1992).

Abad et al. (2003) e Kemp et al. (2005) interpretaram a formação de saponita em rochas metassedimentares, nas proximidades de intrusões ígneas, como um produto de retrometamorfismo da interação de argilominerais dioctaédricos sedimentares com fluidos hidrotermais magnesianos.

$\mathrm{Na}$ Formação Irati, a presença de saponita sedimentar em níveis sem influência do halo térmico e principalmente a composição química das rochas pelíticas - conteúdo em $\mathrm{Al}_{2} \mathrm{O}_{3}$ menor que 7\% (Anjos 2003) - descartam a possibilidade da sua formação a partir de minerais dioctaédricos. Além disso, toda a seqüência sedimentar, independente da presença de intrusões, é pobre em argilominerais aluminosos.

O que se observa é uma tendência de ordenamento da estrutura cristalina tanto da saponita como do talco em direção à intrusão, como resposta ao aumento da temperatura, além da formação de novos cristais a partir de um sistema originalmente magnesiano.

Aspectos texturais das rochas metassedimentares do halo, como a preservação das feições sedimentares e ausência de feições proeminentes de hidrotermalismo, indicam que a saponita, o quartzo e a dolomita, componentes principais das rochas sedimentares sem influência térmica da soleira, seriam os principais minerais reagentes para a formação da paragênese metamórfica: talco, calcita, lizardita, plagioclásio e piroxênio, além da saponita metamórfica.

Considerando-se que a temperatura gerada pela intrusão aumenta das regiões periféricas ao halo em direção à soleira, nas áreas mais afastadas encontram-se as paragêneses formadas em temperaturas relativamente menores: talco + calcita e lizardita + calcita, enquanto

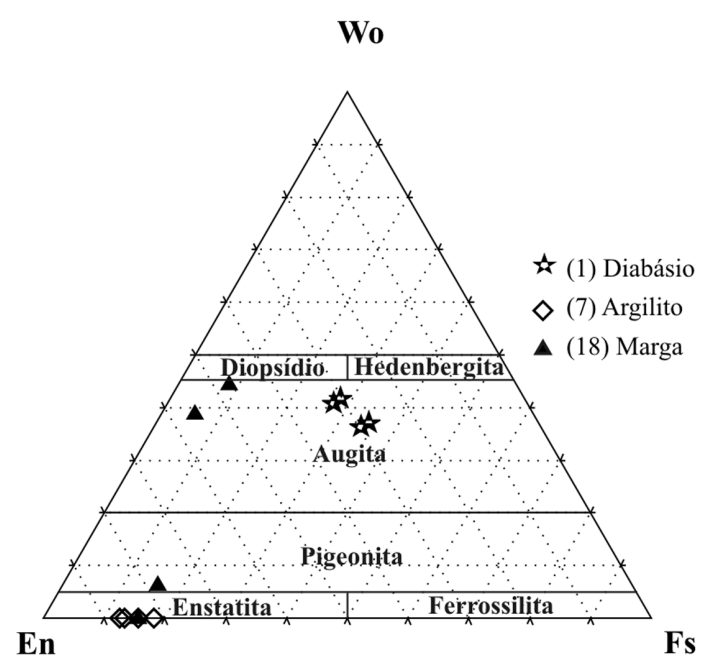

Figura 8 - Projeção da composição química de piroxênios no diagrama Wo-En-Fs (Morimoto 1988). As análises químicas foram obtidas por microssonda eletrônica.

próximo à intrusão a paragênese piroxênio + plagioclásio formou-se em temperaturas mais elevadas. Entretanto, a disposição heterogênea das zonas metamórficas - acima e abaixo da soleira - não parece condicionada somente pela temperatura, e será discutido adiante.

$\mathrm{O}$ aparecimento concomitante de talco e calcita pode ser explicado pela seguinte reação clássica (Equação 1):

$$
\begin{gathered}
3 \mathrm{CaMg}\left(\mathrm{CO}_{3}\right)_{2}+4 \mathrm{SiO}_{2}+\mathrm{H}_{2} \mathrm{O} \rightarrow \\
\text { dolomita } \\
\underset{\mathrm{Mg}_{3} \mathrm{Si}_{4} \mathrm{O}_{10}(\mathrm{OH})_{2}}{\text { quartzo }}+3 \mathrm{CaCO}_{3}+3 \mathrm{CO}_{2} \uparrow \\
\text { talco calcita }
\end{gathered}
$$

Na reação acima pode se considerar também a formação da serpentina a partir de dolomita e quartzo, uma vez que esta possui composição química e estabilidade térmica semelhantes às do talco (Deer et al. 1974). A formação de talco ou lizardita estaria condicionada à disponibilidade de sílica, cuja quantidade é menor para a formação da lizardita (Equação 2):

$$
\begin{aligned}
& 3 \mathrm{CaMg}\left(\mathrm{CO}_{3}\right)_{2}+2 \mathrm{SiO}_{2}+2 \mathrm{H}_{2} \mathrm{O} \rightarrow \\
& \text { dolomita quartzo } \\
& \mathrm{Mg}_{3} \mathrm{Si}_{2} \mathrm{O}_{5}(\mathrm{OH})_{4}+3 \mathrm{CaCO}_{3}+3 \mathrm{CO}_{2} \uparrow \\
& \text { serpentina calcita }
\end{aligned}
$$

A dependência da disponibilidade de sílica explica, para a zona da serpentina, o aparecimento preferencial de lizardita nas rochas carbonáticas e de talco nos pelitos.

Diversas reações [(3) (4) (5) (6)] foram propostas para a gênese do piroxênio em rochas silicáticas com contribuição carbonática no sistema $\mathrm{SiO}_{2}-\mathrm{MgO}$ CaO-H $\mathrm{H}_{2}-\mathrm{CO}_{2}$ (Yoder 1952, Kitahara et al. 1966 e Skippen 1974) (Equações 3 a 6): 


$$
\begin{aligned}
& \underset{\text { dolomita }}{\mathrm{CaMg}\left(\mathrm{CO}_{3}\right)_{2}}+\underset{\text { quartzo }}{2 \mathrm{SiO}_{2}} \rightarrow \underset{\text { diopsídio }}{\mathrm{CaMgSi}_{2} \mathrm{O}_{6}}+2 \mathrm{CO}_{2} \uparrow \\
& \underset{\text { alco }}{\mathrm{Mg}_{3} \mathrm{Si}_{4} \mathrm{O}_{10}(\mathrm{OH})_{2}}+\underset{\text { calcita }}{3 \mathrm{CaCO}_{3}}+\underset{\text { quartzo }}{2 \mathrm{SiO}_{2}} \rightarrow \\
& \underset{\text { aalco }}{3 \mathrm{CaMgi}_{2} \mathrm{O}_{6}}+\mathrm{H}_{2} \mathrm{O}+3 \mathrm{CO}_{2} \uparrow \\
& \text { diopsídio }
\end{aligned}
$$

$$
\underset{\text { talco }}{\mathrm{Mg}_{3} \mathrm{Si}_{4} \mathrm{O}_{10}(\mathrm{OH})_{2}} \rightarrow \underset{\text { enstatita }}{3 \mathrm{MgSiO}_{3}}+\underset{\text { quartzo }}{\mathrm{SiO}_{2}}+\mathrm{H}_{2} \mathrm{O}
$$

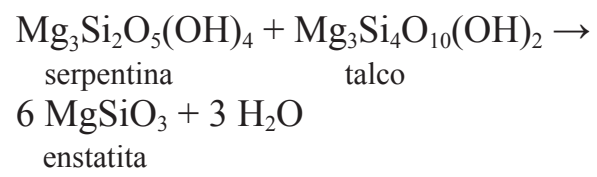

Nas rochas da Formação Irati, as reações (3), (4), (5) e (6) poderiam ter ocorrido, uma vez que todos os minerais participantes dessas equações estão presentes na zona do piroxênio. Por outro lado, o piroxênio formou-se em rochas constituídas predominantemente pela saponita (argilito e marga), sugerindo a possibilidade da sua formação diretamente desse argilomineral. Nessas rochas, além do piroxênio ocorre também o plagioclásio metamórfico, disperso na matriz e substituindo carapaças de ostracodes. A partir dos dados de microssonda eletrônica e raios X da saponita e do piroxênio desses níveis, as seguintes reações metamórficas são propostas (Equações 7 e 8) :

$$
\begin{aligned}
& (\mathrm{Ca}, \mathrm{Na})_{\mathrm{x}}\left(\mathrm{Mg}_{4,5}, \mathrm{Fe}_{1}, \mathrm{Al}_{0,5}\right)\left(\mathrm{Si}_{7}, \mathrm{Al}_{1}\right) \mathrm{O}_{20}(\mathrm{OH})_{4}+2 \mathrm{SiO}_{2} \rightarrow \\
& 0,6 \leq x \leq 1 \text { saponita quartzo }
\end{aligned}
$$

$3\left(\mathrm{Mg}_{1,5}, \mathrm{Fe}_{0,33}, \mathrm{Al}_{0,17}\right) \mathrm{Si}_{2} \mathrm{O}_{6}+(\mathrm{Na}, \mathrm{Ca})\left(\mathrm{Si}_{3}, \mathrm{Al}_{1}\right) \mathrm{O}_{8}+2 \mathrm{H}_{2} \mathrm{O}$ piroxênio (enstatita) plagioclásio

$(\mathrm{Ca}, \mathrm{Na})_{x}\left(\mathrm{Mg}_{4,5}, \mathrm{Fe}_{1}, \mathrm{Al}_{0,5}\right)\left(\mathrm{Si}_{7}, \mathrm{Al}_{1}\right) \mathrm{O}_{20}(\mathrm{OH})_{4}+8 \mathrm{SiO}_{2}+$ $0,6 \leq x \leq 1 \quad$ saponita quartzo $6 \mathrm{CaCO}_{3} \rightarrow 6 \mathrm{Ca}\left(\mathrm{Mg}_{0,75}, \mathrm{Fe}_{0,17}, \mathrm{Al}_{0,08}\right) \mathrm{Si}_{2} \mathrm{O}_{6}+$ calcita piroxênio (diopsídio)

$(\mathrm{Na}, \mathrm{Ca})\left(\mathrm{Si}_{3}, \mathrm{Al}_{1}\right) \mathrm{O}_{8}+2 \mathrm{H}_{2} \mathrm{O}+6 \mathrm{CO}_{2} \uparrow$ plagioclásio

Na reação (7), a saponita e o quartzo formam um piroxênio com composição de enstatita, que é observado tanto no argilito como na marga. Os álcalis e o Al da saponita, que segundo os dados de microssonda eletrônica aparecem em quantidades muito pequenas no piroxênio, associam-se ao Si para formar o plagioclásio. Na reação (8), a presença da calcita entre os reagentes (saponita e quartzo) possibilita a formação de um piroxênio com um conteúdo adicional de $\mathrm{Ca}$, como ocorre na marga. Nesta, a formação de piroxênios com composição desde enstatita até próxima de diopsídio, variando a quantidade dos componentes En e Wo, estaria vinculada à disponibilidade de calcita, que pode variar dentro das lâminas sedimentares.
A temperatura de formação do piroxênio indica $\mathrm{o}$ ápice da temperatura atingida nas rochas encaixantes. No sistema $\mathrm{MgO}-\mathrm{SiO}_{2}-\mathrm{H}_{2} \mathrm{O}$, a formação de enstatita e quartzo a partir do talco ocorre em temperaturas entre 560 a $650^{\circ} \mathrm{C}$, considerando-se uma pressão de $1 \mathrm{kbar}$ (Berman, 1988; Evans \& Guggenhein, 1988). Em rochas carbonáticas do Cambriano, a temperatura de formação do piroxênio em uma auréola metamórfica foi estimada em $475-575^{\circ} \mathrm{C}$ (Moore \& Kerrick 1976, Granath et al. 1983).

Dados experimentais têm mostrado a formação de piroxênio, em sistemas com $\mathrm{SiO}_{2}-\mathrm{Fe}_{2} \mathrm{O}_{3}-\mathrm{MgO}-\mathrm{NaO}$ $\mathrm{H}_{2} \mathrm{O}$, à partir de temperaturas de $100-300^{\circ} \mathrm{C}$, a até $1 \mathrm{kbar}$ (Harder 1976, Redhammer et al. 2000, Decarreau et al. 1987, 2004).

Dessa forma, na Zona do Piroxênio, poderiam ser estimadas temperaturas mínimas entre $300-500^{\circ} \mathrm{C}$ para a formação do piroxênio. A influência térmica sobre as rochas da zona da serpentina e do talco não está clara, visto que o talco e a lizardita podem ser estáveis desde temperaturas ambientes a até temperaturas de cerca de 400 a $600^{\circ} \mathrm{C}$ (Deer et al. 1974).

$\mathrm{O}$ posicionamento dos minerais metamórficos em relação à intrusão demonstra que o sistema não se comportou da mesma forma abaixo e acima da soleira. Em ambos os contatos - superior e inferior - com a soleira, o talco e a serpentina estão presentes, ao lado da saponita. Entretanto, somente na porção superior ocorre a formação de piroxênio, como micro-cristais euédricos dispersos na matriz argilosa. A distribuição assimétrica das zonas de metamorfismo de contato parece condicionada ao deslocamento do fluido aquoso formado em resposta do aquecimento. Na porção subjacente à intrusão, o fluído aquoso teria sido confinado pelo corpo ígneo, situação esta que impediu a sua fuga do sistema, formando minerais hidratados. Na porção superior, cujo pacote sedimentar a partir de 2 metros da intrusão é constituído por sedimentos silto-arenosos da Formação Corumbataí, teria havido a fuga de flúido, e a formação de piroxênio e plagioclásio.

CONCLUSÃO Na pedreira SUCAL, os pelitos e rochas carbonáticas da Formação Irati não afetados pelo halo térmico são constituídos predominantemente por saponita e dolomita, respecivamente, contendo ainda proporções variáveis de quartzo, ilita, e caolinita. Sob influência térmica, além desses minerais, ocorrem talco, calcita, lizardita, piroxênio e plagioclásio. A formação desses minerais metamórficos está vinculada, além da distância da soleira, à composição e textura inicial da rocha encaixante e ao posicionamento em relação à intrusão, sendo distinta acima e abaixo desta.

A ausência da dolomita nas rochas carbonáticas próximas à soleira pode ser explicada pela sua decomposição na formação de calcita, talco e serpentina.

O talco, a serpentina e o piroxênio são minerais índices para três zonas de metamorfismo de contato: a Zona do Talco, entre 1,5 e 5,5m abaixo da soleira; a Zona da Serpentina, desde o contato inferior com a intrusão a até $1,5 \mathrm{~m}$ abaixo desta; e a Zona 
do Piroxênio, do contato superior com a soleira a até $1 \mathrm{~m}$ acima desta.

A disposição assimétrica das zonas metamórficas demonstra que o sistema se comportou de maneira heterogênea acima e abaixo da intrusão. O confinamento de fluido aquoso na porção subjacente à intrusão favoreceu a formação de minerais hidratados (saponita, talco, lizardita), enquanto seu escape na porção superior possibilitou a formação de piroxênio e plagioclásio.

A comparação da mineralogia de rochas do halo térmico com rochas sem influência da intrusão mostra que as reações metamórficas provocadas pela soleira de cerca de $13 \mathrm{~m}$ ocorre a no mínimo $1 \mathrm{~m}$ acima e $5,5 \mathrm{~m}$ abaixo desta, atingido temperaturas mínimas entre 300 $500^{\circ} \mathrm{C}$ na Zona do Piroxênio.

Agradecimentos Os autores agradecem à Pedreira SUCAL pela cessão de amostras para estudo científico, e ao suporte financeiro do projeto CTPETRO/CNPQ (processo 471907/01-4 NV). A primeira autora agradece ao $\mathrm{CNPq}$, pela bolsa de doutorado, e aos professores da Université de Poitiers: Dr. A. Meunier e Dr. A. El Albani, pelas discussões a respeito das reações metamórficas de argilominerais.

\section{Referências}

Abad I., Jiménez-Millán J., Molina J.M., Nieto F. Vera J.A. 2003. Anomalous reverse zoning of saponite and corrensite caused by contact metamorphism and hydrotermal alteration of marly rocks associed with subvolcanic bodies. Clays and Clay Minerals, 51(5):543-554.

AGÊNCIA GOIANA DE DESENVOLVIMENTO INDUSTRIAL (AGIM). 2000. Mapa de Geologia e Recursos Minerais de Goiás e Distrito Federal. Goiânia, Diretoria de Mineração e Recursos Minerais, mapa geológico, escala 1:500.000.

Akbulut A. \& Kadir S. 2003. The geology and origin of sepiolite, palygorskite and saponite in Neogene lacustrine sediments of the Serinhisar-Acipayam basin, Denizli, Sw Turkey. Clays and Clay Minerals, 51(3):279-292.

Almeida C.M. 2005. Taxonomia e paleoecologia de ostracodes do Permiano da bacia do Paraná, Estado de Goiás, Brasil: Considerações paleoambientais e cronoestratigráficas. Dissertação de Mestrado, Instituto de Geociências, Universidade de Brasília, 59p.

Amaral S.E. 1971. Geologia e petrologia da Formação Irati (Permiano) no Estado de São Paulo. Boletim Instituto de Geociências e Astronomia, 2:8-81.

Anjos C.W.D. 2003. A influência térmica de intrusões ígneas sobre pelitos e rochas carbonáticas da Formação Irati, em Goiás. Dissertação de Mestrado, Instituto de Geociências, Universidade de Brasília, 101p.

Anjos C.W.D. \& Guimarães E.M. 2003. Evidências de Metamorfismo de Contato nas rochas da Formação Irati, em Goiás. In: SBGq., Congresso Brasileiro de Geoquímica, 9, Resumos Expandidos, p.587-589.

Anjos C.W.D., Guimarães E.M., Do Carmo D.A., Almeida C.M., Marques-Toigo M. 2003. Caracterização de folhelho microfossilífero de região com intrusões ígneas, Formação Irati (Permiano) - Estado de Goiás, Brasil. In: SBP, Congresso Brasileiro de Paleontologia, 18, Brasília, Boletim de Resumos, 48-49.

April R.H. 1980. Regularly Interestratified Chlorite/Vermiculite in Contact Metamorphosed Red Beds, Newark Group, Connecticut Valley. Clays and Clay Minerals, 28(1):1-11.

Araújo L.M., Trigüis J.A., Cerqueira J.R., Freitas L.C.S. 2000. The atypical Permian petroleum system of the Paraná Basin, Brazil. In: Mello M.R. \& Katz B.J. (eds.) Petroleum systems of South Atlantic margins. AAPG
Memoir, 73:377-402.

Araújo L.M., Scherer R.R., C.M.S. 2001. Seqüências Deposicionais Irati: Arcabouço químio-estratrigráfico e inferências paleoambientais. Ciência-Técnica-Petróleo, 20:193-202.

Aronson J.L. \& Lee M.C. 1986. K/Ar Systematics of Bentonite and Shale in a Contact Metamorphic Zone, Cerrillos, New Mexico. Clays and Clay Minerals, 34(4):483-487.

Barbosa O. \& Gomes F.A. 1958. Pesquisa de Petróleo na Bacia do Rio Corumbataí, Estado de São Paulo. Divisão de Geologia e Mineralogia do DNPM, Boletim 171, 40p.

Berman R.G. 1988. Internally-Consistent Thermodynamic Data for Minerals in the System $\mathrm{Na}_{2} \mathrm{O}-\mathrm{K}_{2} \mathrm{O}-\mathrm{CaO}-\mathrm{MgO}-$ $\mathrm{FeO}-\mathrm{Fe}_{2} \mathrm{O}_{3}-\mathrm{Al}_{2} \mathrm{O}_{3}-\mathrm{SiO}_{2}-\mathrm{TiO}_{2}-\mathrm{H}_{2} \mathrm{O}-\mathrm{CO}_{2}$. Journal of Petrology, 29:445-522.

Bouchet A., Meunier A., Sardini P. 2000. Minéreux argileux - Structures cristallines - Identification par diffraction de rayons $X$. Elf éditions, 136p.

Bühmann C. 1992. Smectite-to-illite conversion in a geothermally and lithologically complex permian sedimentary sequence. Clays and Clay Minerals, 40(1):53-64.

Chamley H. 1989. Clay Sedimentology. Berlin, Ed.SpringerVerlag, 623p.

Decarreau A., Bonnin D., Badaut-Trauth D., Couty R., Kaiser P. 1987. Synthesis and crystallogenesis of ferric smectite by evolution of $\mathrm{Si}-\mathrm{Fe}$ coprecipitates in oxidizing conditions. Clay Minerals; 22(2):207-223.

Decarreau A., Petit S., Vieillard P., Dabert N. 2004. Hydrothermal synthesis of aegirine at $200{ }^{\circ} \mathrm{C}$. European Journal of Mineralogy, 16:85-90.

Deer W.A., Howie R.A., Zussman J. 1974. An Introduction to the Rock Forming Minerals. London, Longman Group Limited, 558p.

Ehrmann W., Setti M., Marinoni L. 2005. Clay minerals in Cenozoic sediments off Cape Roberts (McMurdo Sound, Antarctica) reveal palaeoclimatic history. Palaeogeography, Palaeoclimatology, Palaeoecology, 229:187-211.

Eiras J.F. \& Wanderley Filho J.R. 2003. Sistemas Petrolíferos Ígneo-Sedimentares. In: ABPG, Congresso Brasileiro de P\&D em Petróleo \& Gás, 2, atas, CD-ROM.

Evans B.W. \& Guggenhein S. 1988. Talc, Pyrophyllite, and Related Minerals. In: Bailey S.W. (ed.) Hydrous Phyllosilicates. Mineralogical Society of America, Reviews 
in Mineralogy, 19:225-294.

Girardi V.A.V., Melfi A.J., Amaral S.E. 1978. Efeitos Termais Associados aos Diabásios Mesozóicos da Bacia do Paraná. Boletim do Instituto de Geociências USP, 9:47-55.

Gomes J.B.P. 1959. Algumas observações sobre as intrusões de diabásio na Bacia Sedimentar do Paraná. Boletim Técnico da Petrobrás, 2:7-12.

Granath V.C.H., Papike J.J., Labotka T.C. 1983. The Notch Peak Contact Metamorphic Aureole, Utah: Petrology of the Big Horse Limestone Member of the Orr Formation. Geological Society of American Bulletin, 94(07):889906.

Harder H. 1976. Nontronite syntesis at low temperature. Chemical Geology, 18:169-180.

INTERNATIONAL CENTRE FOR DIFFRACTION DATA (ICCD). 1996. Powder Diffraction File. Pennsylvania, U.S.A. (www.icdd.com), CD-ROM.

Jaeger J.C. 1957. The temperature in the neighborhood of a cooling intrusive sheet. American Journal of Science, 255:306-318.

Kemp S.J., Rochelle C.A., Merriman R.J. 2005. Back-reacted saponite in Jurassic mudstones and limestones intruded by a Tertiary sill, Isle of Skye. Clay Minerals, 40:263282.

Kitahara S., Takeneuchi S., Kennedy G.C. 1966. Phase relations in the system $\mathrm{MgO}-\mathrm{SiO}_{2}-\mathrm{H}_{2} \mathrm{O}$ at high temperatures and pressures. American Journal of Science, 264(3):223233.

Mac Gregor J.H. 1908. Mesosaurus Brasiliensis nov. sp. do Permiano do Brasil. In: White I.C. (ed.) Relatório da Comissão de Estudos das Minas de Carvão de Pedra do Brasil, 1 de julho de 1904 a 31 de maio de 1906, DNPM, Parte II, p.301-336.

Meunier A. 2003. Argiles. Gordon \& Breach ed., 433p.

Milani E.J., França A.B., Schneider R.L. 1994. Bacia do Paraná. Boletim de Geociências da Petrobrás, 8(1):69-82.

Moore J.N. \& Kerrick D.M. 1976. Equilibria in Siliceous Dolomites of the Alta Aureole, Utah. American Journal of Science, 276(4):502-524.

Morimoto N., Fabries J., Ferguson A.K., Ginzburg I.V., Ross M., Seifert F.A., Zussman J., Aoki K., Gottardi G. 1988. Nomenclature of Pyroxenes. American Mineralogist, 73(9-10):1123-1133.

Nadeau P.H. \& Reynolds Jr. R.C. 1981. Burial and Contact Metamorphism in the Mancos Shale. Clays and Clay Minerals, 29(4):249-259.

Northfleet A.A., Medeiros R.A., Mühlmann H. 1969. Reavaliação dos Dados Geológicos da Bacia do Paraná. Boletim Técnico da Petrobrás, 12(3):291-346.

Padula V.T. 1968. Estudos geológicos da Formação Irati, sul do Brasil. Boletim Técnico da Petrobrás, 11(3):407430.

Petri S. \& Fúlfaro V.J. 1983. Geologia do Brasil. São Paulo, Editora da Universidade de São Paulo, 631p.

Post J.L. 1984. Saponite from near Ballarat, California. Clays and Clay Minerals, 32(2):147-153.
Redhammer G.J., Amthauer G., Lottermoser W., Treutmann W. 2000. Synthesis and structural properties of clinopyroxenes of the hedenbergite $\left(\mathrm{CaFe}^{2+} \mathrm{Si}_{2} \mathrm{O}_{6}\right)$ - aegirine $\left(\mathrm{NaFe}^{3+} \mathrm{Si}_{2} \mathrm{O}_{6}\right)$ solid-solution series. European Journal of Mineralogy, 12(1):105-120.

Sant'Anna L.G., Clauer N., Cordani U.G., Riccomini C., Velázquez V.F., Liewig N. 2006. Origin and migration timing of hydrothermal fluids in sedimentary rocks of the Paraná Basin, South America. Chemical Geology, 230:1-21.

Santos R.V., Dantas E., Alvarenga C.J.S., Berdran F., Guimaraes E.M., Oliveira C.G., Marques-Toigo M., Mendonca Filho J.G., Anjos C.W.D., Medeiros S.R. 2003. Geochemical and Thermal Effects of Basic Intrusives Rocks on the Irati Formation - Northewestern Paraná Basin. In: South American Symposium on Isotope Geology, 4, Short Papers, p.776-779.

Setti M., Marinoni L., López-Galindo A. 2004. Mineralogical and geochemical characteristics (major, minor, trace elements and REE) of detrital and authigenic clay minerals in a Cenozoic sequence from Ross Sea, Antarctica. Clay Minerals, 39:405-422.

Schneider R.L., Mühlmann H., Tommasi E., Medeiros R.A., Daemon R.F., Nogueira A.A. 1974. Revisão Estratigráfica da Bacia do Paraná. In: SBG, Congresso Brasileiro de Geologia, 28, Anais, p. 41-65.

Skippen G. 1974. An experimental model for low pressure metamorphism of siliceous dolomitic marble. American Journal of Science, 274(5):487-509.

Vergo N. \& April R.H. 1982. Interestratified Clay Minerals in Contact Aureoles, West Rock, Connecticut. Clays and Clay Minerals, 30(3):237-240.

Wanderley Filho J.R., Travassos W.A.S., Alves D.B. 2006. O diabásio nas bacias paleozóicas amazônicas - herói ou vilão? Boletim de Geociências da Petrobrás, 14(1):177184.

White D. 1908. Flora Fóssil das Coal Measures do Brasil. In: White I.C. (ed.) Relatório da Comissão de Estudos das Minas de Carvão de Pedra do Brasil, 1 de julho de 1904 a 31 de maio de 1906, DNPM, Parte III, p.337-617.

White I.C. 1908a. Relatório sobre as coal measures e rochas associadas, do sul do Brasil. In: White I.C. (ed.) Relatório da Comissão de Estudos das Minas de Carvão de Pedra do Brasil, 1 de julho de 1904 a 31 de maio de 1906, DNPM, Parte I, p.1-300.

Yalçin H. \& Bozkaya O. 2006. Mineralogy and Geochemistry of Paleocene Ultramafic- and Sedimentary -Hosted Talc deposits in the Southern part of the Sivas Basin, Turkey. Clays and Clay Minerals, 54(3):333-350.

Yoder H.S.Jr. 1952. The $\mathrm{MgO}-\mathrm{Al}_{2} \mathrm{O}_{3}-\mathrm{SiO}_{2}-\mathrm{H}_{2} \mathrm{O}$ system and related metamorphic facies. American Journal of Science, 250:569-627.

Manuscrito ID 10300

Submetido em 16 de janeiro de 2008 Aceito em 12 de dezembro de 2008 Sistema eletrônico de submissão 